\title{
TORSIONAL VIBRATIONS OF CAR CRANKSHAFT ENGINE TAKING INTO ACCOUNT ELEMENTS OF TRANSMISSION
}

\author{
Farit Khaliullin $^{1,2}$, Tagir Vagizov ${ }^{2}$, Renat Shakirov ${ }^{3}$, Ivan Deryushev ${ }^{3}$ \\ ${ }^{1}$ Kazan National Research Technical University named after A. N. Tupolev, Russia; ${ }^{2}$ Kazan State \\ Agrarian University, Russia; ${ }^{3}$ Izhevsk State Agricultural Academy, Russia \\ khaliullin_kai_adis@mail.ru,toha-174@mail.ru,renmar@mail.ru,deryshev_ivan@mail.ru
}

\begin{abstract}
The article is devoted to assessing the influence of the parameters of car transmission elements on the nature of the resulting torsional vibrations of the crankshaft of its power plant. As a rule, at present, the study of torsional vibrations of the crankshafts of piston internal combustion engines is carried out separately from the conditions of their operation. Only the operating modes of the engines, the torques of individual cylinders are considered, taking into account the order of operation and the angle between the flashes. If necessary, instead of a linear equivalent torsional circuit, branched circuits are considered that take into account the influence of individual engine mechanisms. Perturbing moments in such schemes occur only on the crank of the crankshaft. Only engine operating modes are considered, which take into account the elements of the car transmission and their influence on the nature of torsional vibrations along the entire length of the driven shaft. The moments of inertia of each transmission element and the stiffness of the equivalent torsional circuit sections are determined. The oscillation equations of the equivalent design scheme are drawn up taking into account the transmission elements. The values of the natural oscillation frequencies are determined by solution of homogeneous differential equations. The influence of the external environment can be estimated by applying perturbing the moment per equivalent mass replacing elements of the undercarriage of the car. Given the large values of the moments of inertia of the elements of transmission and the frequency range of their own vibrations, it is possible to explain the displacement of the amplitude of vibrations and their nodes. The considered technique is of interest for scientific and technical workers, and designers involved in the design of transmission elements for motor vehicles.
\end{abstract}

Keywords: transmission, car, scheme, rigidity, shaft, elasticity, deformation, engine, crankshaft, oscillation.

\section{Introduction}

During operation of tractor engines, torsional vibrations occur not only in the engine itself, but also in the engine-transmission-drive wheel system. The source of such vibrations is the torques acting on the cranks and the phase-shifted torques of the various cylinders. It is very important to predict such phenomena at the design stage, which reduces further changes in the design and kinematic parameters of the transmission $[1 ; 2]$. The correct choice of the dimension of the calculation scheme strongly affects the results obtained. Correct determination of the elastic and inertial parameters of the elements of the design scheme depends on its natural oscillation frequencies and resonant operating modes [3; 4]. The calculation of torsional vibrations of the crankshafts of tractor engines is usually carried out separately for the engine itself. In operational conditions, when the engine is running as part of a mobile transport vehicle, additional masses are added to the oscillatory circuit, which leads to changes in the parameters of the oscillatory process $[5 ; 6]$. As a result, it is necessary to change the parameters of the designed torsional vibration dampers [7] to increase the efficiency of their operation. As a rule, such works are accompanied by experimental studies to clarify the influence of transmission elements on the parameters of the oscillatory process $[7 ; 8]$.

\section{Status of the issue}

The typical method of calculating the crankshaft consists of the following steps [9-11]:

1. selection of an equivalent torsion circuit and calculating its parameters;

2. determination of the natural frequencies of torsional vibrations and the corresponding resonant modes of engine operation;

3. harmonic analysis of the engine torque at all resonant operating modes;

4. calculation of the motor mass oscillation amplitudes;

5. determination of emerging additional elastic moments and stresses from them.

This technique is described in $[12 ; 13]$ and we will not talk about it in detail.

For a comparative analysis, consider the O6 opposed spark engine in the composition of a midrange car with the following characteristics:

- nominal power/rotation frequency $-N_{e N}=170 \mathrm{~kW} / n_{e N}=5800 \mathrm{rpm}$; 
- $\quad$ cylinder bore/piston stroke $-D=0.095 \mathrm{~m} / \mathrm{S}=0.073 \mathrm{~m}$;

- diameter/root collar length $-d_{r}=0.055 \mathrm{~m} / l_{r}=0.025 \mathrm{~m}$;

- diameter/connecting rod neck length $-d_{c r}=0.055 \mathrm{~m} / l_{c r}=0.025 \mathrm{~m}$;

- thickness/cheek width $-e=0.008 \mathrm{~m} / h=0.1 \mathrm{~m}$;

- crank radius $-r=0.0366 \mathrm{~m}$;

- layout scheme - oppositional;

- number of cylinders - 6;

- cylinder operation procedure - 1-6-2-4-3-5;

- stroke of the piston $-0.0732 \mathrm{~m}$;

- working volume of the engine $-0.003 \mathrm{~m}^{3}$.

The design parameters of the transmission elements for the selected car are available in the technical literature [14].

For the calculations of the engine for torsional vibrations, a seven-mass equivalent scheme was chosen, the principles of which are shown in Fig. 1.

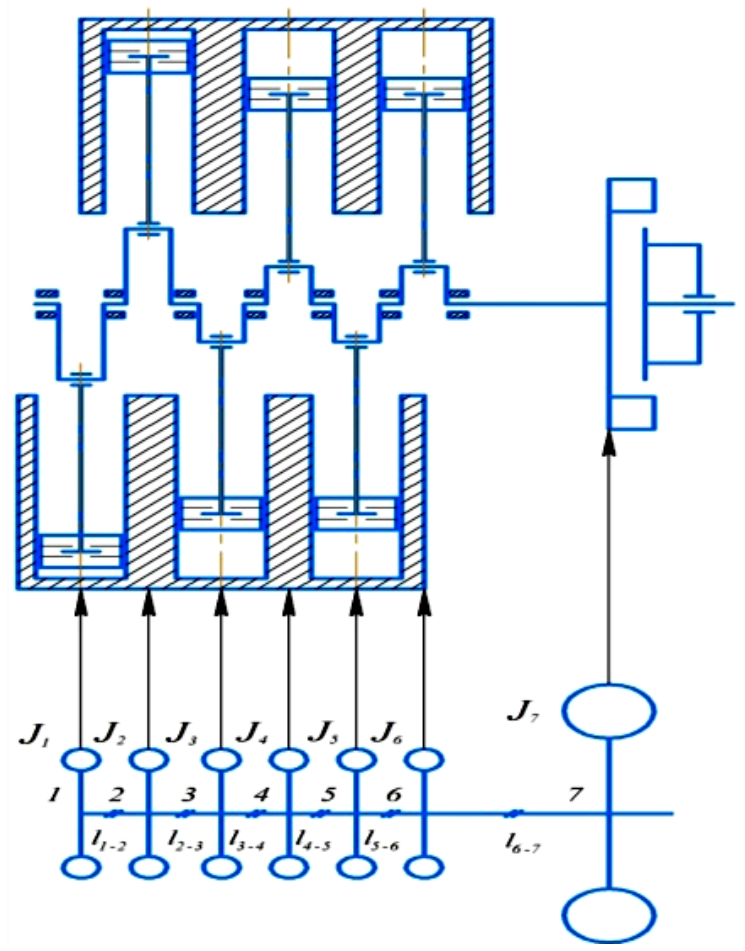

Fig. 1. Valid and calculated diagram of $\mathrm{O6}$ engine: $J_{1}, J_{2}, J_{3}, J_{4}, J_{5}, J_{6}-$ moments of inertia of the motor masses, $J_{7}$ - moment of inertia of the flywheel with the clutch, $l_{\mathrm{i}-\mathrm{i}+1}-$ length between the $i$-th and $i+1$-th sections of the equivalent torsional scheme

Using the computational and graphical method, we determine the parameters of the equivalent torsional circuit (Table 1). To simplify the calculations, we accept the assumption about the identity of the plots between the motor masses [15].

Table 1

Parameters of the equivalent torsional sheme

\begin{tabular}{|c|c|c|}
\hline Moment of inertia $\boldsymbol{J}_{\boldsymbol{i}}, \mathbf{k g} \cdot \mathbf{m}^{\mathbf{2}}$ & Reduced length $\boldsymbol{l}_{\boldsymbol{i}-\boldsymbol{i}+\mathbf{1}}, \mathbf{m}$ & Plot stiffness, $\boldsymbol{C}_{\boldsymbol{i}-\boldsymbol{i}+\mathbf{1}}, \mathbf{N} \cdot \mathbf{m}$ \\
\hline$J_{1}=3.627602 \cdot 10^{-3}$ & - & - \\
\hline$J_{2}=3.627602 \cdot 10^{-3}$ & $l_{1-2}=0.0967$ & $\mathrm{C}_{1-2}=3.53993 \cdot 10^{5}$ \\
\hline$J_{3}=3.627602 \cdot 10^{-3}$ & $l_{2-3}=0.0967$ & $\mathrm{C}_{2-3}=3.53993 \cdot 10^{5}$ \\
\hline$J_{4}=3.627602 \cdot 10^{-3}$ & $l_{3-4}=0.0967$ & $\mathrm{C}_{3-4}=3.53993 \cdot 10^{5}$ \\
\hline$J_{5}=3.627602 \cdot 10^{-3}$ & $l_{4-5}=0.0967$ & $\mathrm{C}_{4-5}=3.53993 \cdot 10^{5}$ \\
\hline$J_{6}=3.627602 \cdot 10^{-3}$ & $l_{5-6}=0.0967$ & $\mathrm{C}_{5-6}=3.53993 \cdot 10^{5}$ \\
\hline$J_{7}=1.041727 \cdot 10^{-2}$ & $l_{6-7}=0.0505$ & $\mathrm{C}_{6-7}=6.76655 \cdot 10^{5}$ \\
\hline
\end{tabular}


To determine the natural oscillation frequencies, the application software package "MATLAB" is used and the program for working with spreadsheets "Microsoft Excel".

After holding a range analysis (Fig. 2), the value of the natural frequency is selected $\omega_{0}=2780 \mathrm{~s}^{-1}$.

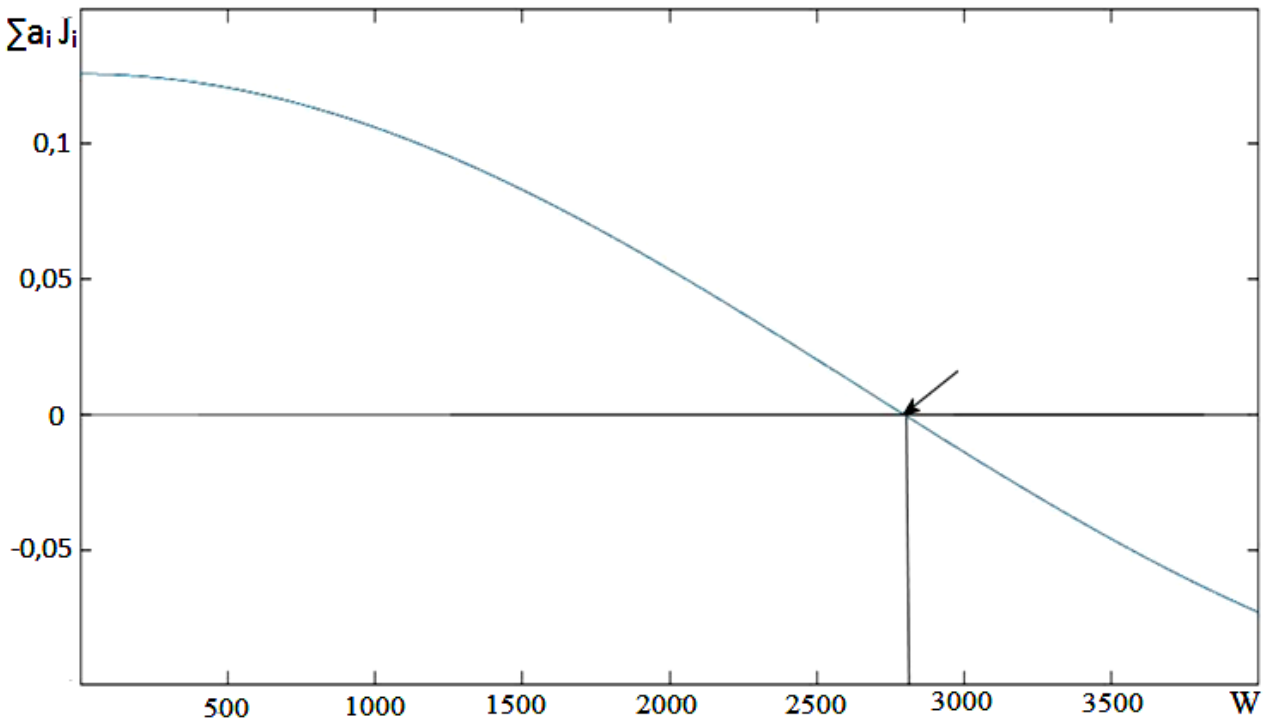

Fig. 2. Determination of the frequency of natural vibrations by the Holzer method

To determine the resonant modes of operation, we use the frequency diagram (Fig. 3).

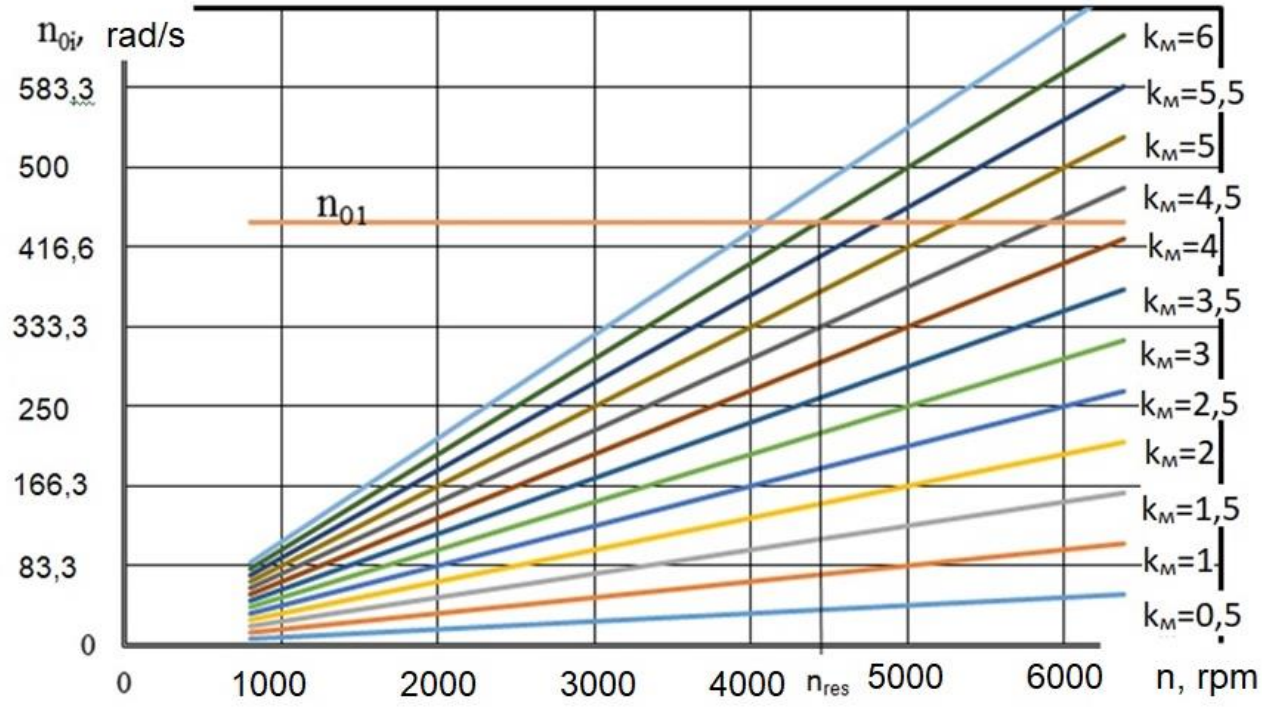

Fig. 3. Definition of resonant operating modes

From the resonance condition $n_{0 i}=n_{k}$, the resonant operating mode is established at $n_{\text {res }}=4426 \mathrm{rpm}$ and $k_{\mu}=6$.

We perform a harmonic analysis of the torque and calculate the motor harmonics.

$$
\mathrm{M}_{t}(t)=\mathrm{M}_{\text {average }}+\sum_{k=0.5}^{15} M_{t} \cdot \sin \left(k_{m} \cdot \varphi+\varphi_{k_{m}}\right),
$$

where $M_{\text {average }}=\frac{1}{N} \sum_{i=0}^{N} y_{i}-$ average torque acting on the knee;

$k_{m}=0.5 \mathrm{k}=0.5 ; 1 ; 1.5 ; \ldots ; 15-$ motor harmonic index;

$\varphi_{k}-k$-th harmonic phase shift.

The harmonic analysis results for the O6 engine are shown in Table 2. 
Harmonic analysis results for $\mathrm{O6}$ engine

\begin{tabular}{|c|c|c|c|c|}
\hline $\boldsymbol{k}$ & $\boldsymbol{A}_{\boldsymbol{k}}$ & $\boldsymbol{B}_{\boldsymbol{k}}$ & $\boldsymbol{M}_{\boldsymbol{k}}$ & $\boldsymbol{\varphi}_{\boldsymbol{k}}$ \\
\hline 1 & -82.863 & -57.248 & 100.715 & 55.360 \\
\hline 2 & 48.629 & 125.322 & 134.427 & 21.208 \\
\hline 3 & -10.995 & -95.504 & 96.134 & 6.567 \\
\hline 4 & 9.373 & -165.810 & 166.074 & -3.236 \\
\hline 5 & 10.108 & -64.273 & 65.062 & -8.937 \\
\hline 6 & -9.445 & -46.893 & 47.834 & 11.388 \\
\hline 7 & 15.508 & -41.563 & 44.362 & -20.462 \\
\hline 8 & -14.784 & 23.591 & 27.841 & -32.075 \\
\hline 9 & 15.685 & -25.313 & 29.778 & -31.784 \\
\hline 10 & -13.556 & 19.321 & 23.602 & -35.054 \\
\hline 11 & 12.987 & -14.687 & 19.605 & -41.485 \\
\hline 12 & -11.208 & 11.564 & 15.979 & -43.640 \\
\hline
\end{tabular}

The next step is to determine the relative amplitudes of motor masses and select the parameters of single-node oscillations (Fig. 4).

Further calculation for additional resonant voltages is subject to a resonance mode with a harmonic $k_{M}=6$, because in this mode we have a resonance with the most dangerous main harmonic, as well as a resonant crankshaft speed $n_{\text {res. }(6,0)}=4426 \mathrm{rpm}$ lies in the operating range of the engine $[16 ; 17]$.

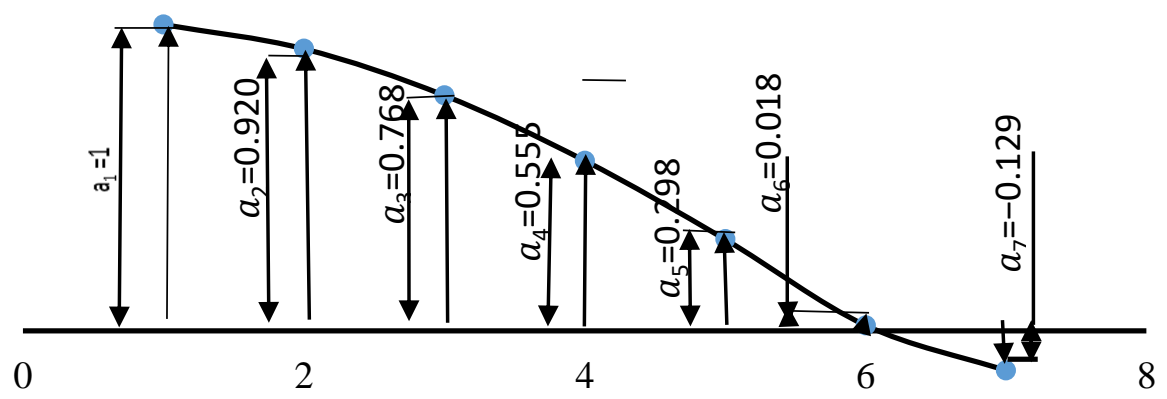

Fig. 4. Single-node shape of the crankshaft oscillation

Then using the formula we determine the absolute amplitude of the oscillations of the first motor mass for the absolute value of the torque:

$$
A_{1}^{*}=\frac{M_{t} \sqrt{\left[\sum_{i=1}^{N} a_{i}^{*} \sin \left(k_{M} \Delta \theta_{1-i}\right)\right]^{2}+\left[\sum_{i=1}^{N} a_{i}^{*} \cos \left(k_{M} \Delta \theta_{1-i}\right)\right]^{2}}}{\xi k_{M} \omega_{I C E} \sum_{i=1}^{N}\left(a_{i}\right)^{2}},
$$

where $\xi$-damping coefficient;

$\omega_{I C E}$ - angular velocity of the engine crankshaft for the design mode.

The calculation results for even harmonics are shown in Table 3.

Table 3

Calculation results for even harmonics

\begin{tabular}{|c|c|c|c|c|c|c|}
\hline$k_{M}$ & 1 & 2 & 3 & 4 & 5 & 6 \\
\hline$M_{t}, \mathrm{~N} \cdot \mathrm{m}$ & 134.43 & 166.07 & 47.83 & 27.84 & 23.602 & 15.979 \\
\hline$A_{1}, \mathrm{rad}$ & 0.001998 & 0.002468 & 0.003792 & 0.000414 & 0.000351 & 0.001267 \\
\hline$A_{2}, \mathrm{rad}$ & 0.001839 & 0.002272 & 0.003492 & 0.000381 & 0.000323 & 0.001166 \\
\hline$A_{3}, \mathrm{rad}$ & 0.001536 & 0.001897 & 0.002915 & 0.000318 & 0.000270 & 0.000974 \\
\hline$A_{4}, \mathrm{rad}$ & 0.001110 & 0.001371 & 0.002107 & 0.000230 & 0.000195 & 0.000704 \\
\hline$A_{5}, \mathrm{rad}$ & 0.000597 & 0.000737 & 0.001133 & 0.000124 & 0.000105 & 0.000378 \\
\hline$A_{6}, \mathrm{rad}$ & 0.000036 & 0.000044 & 0.000068 & 0.0000074 & 0.0000063 & 0.0000228 \\
\hline$A_{7}, \mathrm{rad}$ & -0.0002588 & -0.0003198 & -0.0004913 & -0.0000536 & -0.0000454 & -0.0001641 \\
\hline
\end{tabular}


The last step in the calculations is to determine additional resonant voltages. To do this, we find the values of the elastic moment for each section of the equivalent shaft according to the formula:

$$
M_{e l i-i+1}=c_{i-i+1}\left(A_{i}^{*}-A_{i+1}^{*}\right),
$$

where $c_{i-i+1}-$ stiffness of the equivalent shaft between the $i$ and $i+1$ motor masses.

The calculated values of the elastic moments are given in Table 4.

Table 4

\section{Calculated values of elastic moments}

\begin{tabular}{|c|c|c|c|c|c|c|}
\hline Plot & $1-2$ & $2-3$ & $3-4$ & $4-5$ & $5-6$ & 6-7 \\
\hline & 40.623 & 78.026 & 109.251 & 131.824 & 143.956 & 44 \\
\hline
\end{tabular}

The stresses are calculated on the last section of the shaft, where the greatest elastic moment acts. In our case, this is the last plot.

$$
\tau=\frac{M_{e l}}{W}=\frac{144,687 \times 16 \times 10^{-6}}{3.14 \times 45^{3} \times 10^{-9}}=8,09 \mathrm{MPa},
$$

where $W$ - moment of resistance of the shaft cross section.

Consider the calculation of the torsional vibrations of the engine crankshaft together with the transmission of the car (Fig. 5). In this case, the number of masses of the calculated scheme will grow from 7 to 13 .

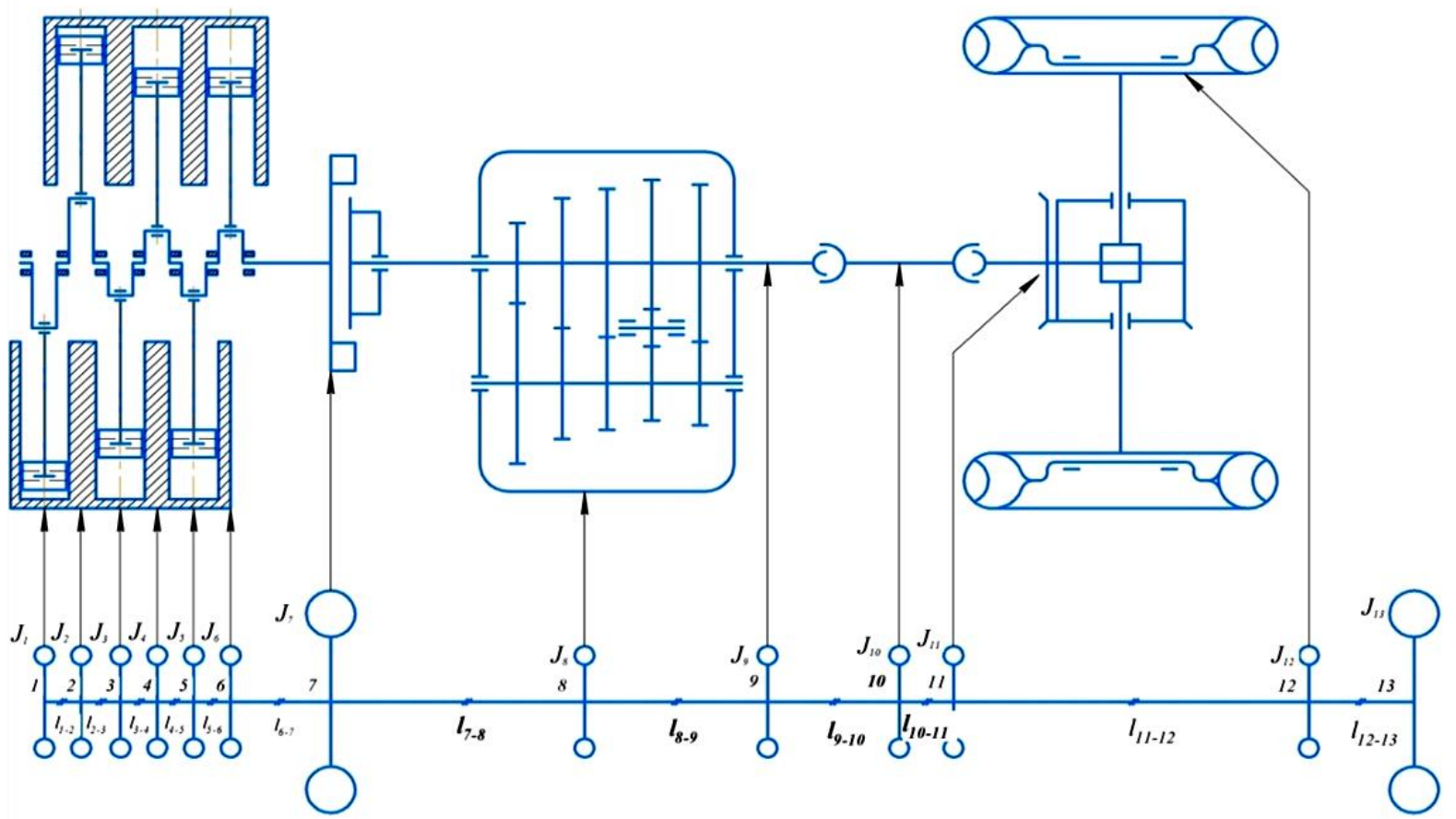

Fig. 5. Valid and calculated schematics of $\mathrm{O6}$ engine with transmission:

$J_{1}, J_{2}, J_{3}, J_{4}, J_{5}, J_{6}$ - moments of inertia of motor masses; $J_{7}$-inertia moment of the flywheel with a clutch; $J_{8}$ - moment of inertia of the primary and secondary shafts with pinions; $J_{9}$ - moment of inertia of the secondary shaft with pinions; $J_{10}$ - moment of inertia of the driveshaft; $J_{11}$ - moment of inertia of differential; $J_{12}$ - moment of inertia of the semi-axes; $J_{13}$ - given moment of inertia of the car at full load; $l_{\mathrm{i}-\mathrm{i}+1}-$ length between the $i$-th and $i+1$-th sections of the equivalent torsional scheme.

By analogy with the previously adopted calculation method, we carry out the calculation for torsional vibrations of the crankshaft-transmission system of the car. The design scheme consists of 13 masses. Harmonic torque analysis remains the same.

Additional parameters of the equivalent torsional circuit are shown in Table 5. 
Additional parameters of the equivalent torsional circuit

\begin{tabular}{|c|c|c|}
\hline Moment of inertia $\boldsymbol{J}_{\boldsymbol{i}} \mathbf{\text { kg}} \cdot \mathbf{m}^{\mathbf{2}}$ & Reduced length $\boldsymbol{l}_{\mathbf{i - i + 1}}, \mathbf{m}$ & Plot stiffness, $\boldsymbol{C}_{\boldsymbol{i - i + 1} \mathbf{1}}, \mathbf{N} \cdot \mathbf{m}$ \\
\hline$J_{8}=19 \cdot 10^{-4}$ & $l_{7-8}=14.8$ & $C_{7-8}=0.874 \cdot 10^{4}$ \\
\hline$J_{9}=2.36 \cdot 10^{-4}$ & $l_{8-9}=385.95$ & $C_{8-9}=0.0335 \cdot 10^{4}$ \\
\hline$J_{10}=3.01 \cdot 10^{-4}$ & $l_{9-10}=53.23$ & $C_{9-10}=0.243 \cdot 10^{4}$ \\
\hline$J_{11}=1.56 \cdot 10^{-4}$ & $l_{10-11}=759.19$ & $C_{10-11}=0.017 \cdot 10^{4}$ \\
\hline$J_{12}=0.0105$ & $l_{11-12}=778.82$ & $C_{11-12}=0.0166 \cdot 10^{4}$ \\
\hline$J_{13}=0.724$ & $l_{12-13}=231.12$ & $C_{12-13}=0.056 \cdot 10^{4}$ \\
\hline
\end{tabular}

Set a new resonant mode of operation is set at $n_{\text {res }}=17.4 \mathrm{~s}^{-1}$ and $k_{M}=6$.

The calculated values of the absolute amplitudes of oscillations of motor masses for even harmonics are given in Table 6.

Calculated values of the absolute amplitudes of oscillations

Table 6 of motor masses for even harmonics

\begin{tabular}{|c|c|c|c|c|c|c|}
\hline $\boldsymbol{k}_{\boldsymbol{M}}$ & $\mathbf{1}$ & $\mathbf{2}$ & $\mathbf{3}$ & $\mathbf{4}$ & $\mathbf{5}$ & $\mathbf{6}$ \\
\hline$M_{k}, \mathrm{~N} \cdot \mathrm{m}$ & 134.43 & 166.07 & 47.83 & 27.84 & 2.602 & 15,979 \\
\hline$A_{1}, \mathrm{rad}$ & 0.001246 & 0.002002 & 0.003145 & 0.000367 & 0.000291 & 0.001011 \\
\hline$A_{2}, \mathrm{rad}$ & 0.001143 & 0.001945 & 0.003012 & 0.000326 & 0.000285 & 0.000967 \\
\hline$A_{3}, \mathrm{rad}$ & 0.001012 & 0.001897 & 0.002915 & 0.000318 & 0.000270 & 0.000974 \\
\hline$A_{4}, \mathrm{rad}$ & 0.000934 & 0.001371 & 0.002107 & 0.000230 & 0.000195 & 0.000704 \\
\hline$A_{5}, \mathrm{rad}$ & 0.000578 & 0.000737 & 0.001133 & 0.000124 & 0.000105 & 0.000378 \\
\hline$A_{6}, \mathrm{rad}$ & 0.000027 & 0.000044 & 0.000068 & 0.0000074 & 0.0000063 & 0.000228 \\
\hline$A_{7}, \mathrm{rad}$ & 0.000157 & 0.0003198 & 0.0004913 & 0.0000536 & 0.0000454 & 0.000164 \\
\hline$A_{8}, \mathrm{rad}$ & -0.000342 & -0.000573 & -0.000736 & -0.000156 & -0.0001587 & -0.000127 \\
\hline$A_{9}, \mathrm{rad}$ & -0.00256 & -0.00387 & -0.00987 & -0.000693 & -0.000578 & -0.000873 \\
\hline$A_{10}, \mathrm{rad}$ & -0.00637 & -0.00734 & -0.01258 & -0.001025 & -0.000973 & -0.00157 \\
\hline$A_{11}, \mathrm{rad}$ & -0.00845 & -0.00912 & -0.01387 & -0.001578 & -0.001323 & -0.00478 \\
\hline$A_{12}, \mathrm{rad}$ & -0.00893 & -0.00987 & -0.01578 & -0.001934 & -0.002198 & -0.00856 \\
\hline$A_{13}, \mathrm{rad}$ & -0.00967 & -0.01023 & -0.01734 & -0.002498 & -0.004213 & -0.00978 \\
\hline
\end{tabular}

Consider only the plot of the crankshaft (Table 7) and determine for it the elastic moments and emerging additional stress from torsional vibrations.

Table 7

Elastic moments and the resulting additional stresses from torsional vibrations

\begin{tabular}{|l|c|c|c|c|c|c|}
\hline Plot number & $1-2$ & $2-3$ & $3-4$ & $4-5$ & $5-6$ & $6-7$ \\
\hline$M_{e l i-i+1}, \mathrm{~N} \cdot \mathrm{m}$ & 35.545 & 68.274 & 95.597 & 115.349 & 125.964 & 126.604 \\
$\tau=\frac{M_{e l}}{W}=\frac{126,604 \times 16 \times 10^{-6}}{3.14 \times 45^{3} \times 10^{-9}}=7.079 \mathrm{MPa}$.
\end{tabular}

For the calculated section, the additional stresses were reduced by $12 \%$ compared to the calculation of the crankshaft without taking into account the elements of the car transmission. In this case, the oscillation node is shifted in the direction of the car transmission, the resonant modes have lower values.

\section{Conclusions}

The calculation of the torsional vibrations of the crankshafts of car engines can be entered both separately for the engine and taking into account the other elements of the transmission of the torque to the driving wheels. However, the results of the calculations will differ. The use of a multi-mass design scheme of the crankshaft, taking into account the elements of the car transmission, significantly changes the picture of torsional vibrations: the node of single-node vibrations is shifted towards the car transmission, the resonant modes of operation are shifted towards low frequencies. The amplitudes of the motor mass oscillations also change. In our calculations, the oscillation amplitude of the first motor 
mass changed from $A_{1}=0.001998 \mathrm{rad}$ to $A_{1}=0,001246 \mathrm{rad}$, the first resonant frequency changed from $n_{\text {rez }}=4426 \mathrm{rpm}$ to $n_{\text {rez }}=4045 \mathrm{rpm}$. The resulting elastic moment on the most dangerous section 6-7 of the shaft changed from $M_{e l .6-7}=144.687 \mathrm{Nm}$ to $M_{e l .6-7}=124.604 \mathrm{Nm}$. This must be taken into account, when designing and determining the effective modes of operation of torsional vibration dampers of crankshafts.

\section{References}

[1] Douglas V. L., Edson L. D., Sidney A. G. Analysis of torsional vibrations of engines in a dynamometer Preview of effects during clutch disc calibration// Conference Proceedings: SAE 2004 Volume: 2004-01-3247, DOI: 10.4271/2004-01-3247.

[2] Degtyareva T. S., Surkov G. S. Implementation and comparison of methods for calculating the frequencies of natural torsional vibrations in reciprocating compressors//News of higher educational institutions. Mechanical Engineering 11(716) 2019, pp. 19-25.

[3] Grzondzela A., Pochva B., Szymak P. Analysis of the action of a viscous damper of torsional vibrations of the crankshaft based on the transverse vibration of the cylinder block //Solid State Phenomena (volume 236) pp. 145-152, https://doi.org/10.4028/www.scientific.net/SSP.236.145.

[4] Kangshao, Liu C.W., By F.R., Du X.E., Wang X., Hang J.N.Vibration modeling of a diesel engine based on the dynamics of several bodies//Applied Mechanics and Materials.volumes 97-98, pp. 706-711. DOI: 10.4028/www.scientific.net/AMM.97-98.706.

[5] Homik W. Torsional vibration silencers used in vessels propulsion system// Scientific Journals Maritime University of Szczecin Zeszyty Naukowe Akademia Morska w Szczecinie 2014, 40(112) pp. 9-16.

[6] Xia Y., Li H., Wang X.H. Finite element torsion analysis of transmission torsional vibrations for the development of a vehicle with front-wheel drive// Lecture notes on Electrical Engineering 201: 55-72 doi: 10.1007/978-3-642-33832-8-5.

[7] Tverskov B. M. Reducing the stiffness of the damper-as a way to eliminate dangerous vibrations of the transmission// Automotive industry 2010, No. 03, pp. 11-13.

[8] Struchkov V., Klimov A. A., Eresko T. T. Experimental studies of torsional compliance of transmission elements// Sistemy. Methods. Technologies 2016 No 1 (29) pp. 33-39 DOI: 10.18324/2077-5415-2016-1-33-39.

[9] Troy Feese P.E., Charles Hill. Guidelines for preventing torsional vibration problems in reciprocating machinery.San Antonio, Texas, 2002.-45 p.

[10] Wang Y., Lim T. C. Prediction of torsional damping coefficients in reciprocating engine/Journal of sound and vibration. The university of Alabama, 2000, pp. 710-719.

[11]Bejan L., Poterasu V.F. Eigenvalues andeigensensitivities of the crankshaft damped vibration. Buletinulinstitulnipolitehnic.Bucuresti.Sec 5, 1995, №3. pp. 27-32.

[12] Martinek F. Drehschwingungsdampfungbeim Hubkolbenmotor. MTZ: Motortech-nische Zeitschrift, 1998, №3. pp. 172-175.

[13] Chao C.-P., Show S.W., Lee C.-T. Stability of the unison response for a rotating system with multiple tautochronic pendulum vibration absorbers. Transactions of ASME: Journal of appl. Mechanicas. 1997, №1. pp. 149-156.

[14] Chistyakov V.K. Dynamics of Piston and Combined Internal Combustion Engines.- Moscow: Mashinostroenie, 1989. -256 p.

[15] Khaliullin F., Shaikhutdinov R., Shakirov R., Ivanov A. Taking into account construction parameters of crankshaft when evaluating characteristics of its equivalent torsion scheme//19th International Scientific Conference Engineering for Rural Development, ERD 2020; Jelgava; Latvia; 20 - 22 May 2020, pp. 1108-1114.

[16] Khaliullin F.K., Matyashin A.V., Akhmetzyanov R.R., Medvedev V.M., Lushnov M.A. Prospects for using the Bayes algorithm for assessing the technical condition of internal combustion engines //IOP Conference Series: Materials Science and Engineering, Volume 635, 10th International Conference on Mechatronics and Manufacturing (ICMM 2019) 21-23 January 2019, Bangkok, Thailand, doi:10.1088/1757-899X/635/1/012016.

[17] Egorov N., Khaliullin F., Khaliullina Z., Zimina L. Adaptive support for power units of machinetractor unit// 19th International Scientific Conference Engineering for Rural Development, ERD 2020; Jelgava; Latvia; 20 - 22 May 2020, pp. 1737-1742. 